\title{
Em tempos de desumanização: a emergência da crítica ontológica no complexo educacional
}

\section{Patricia Laura Torriglia ${ }^{1}$}

https://orcid.org/0000-0002-4567-6616

Vidalcir Ortigara ${ }^{2}$

https://orcid.org/0000-0002-0232-2164

\author{
Astrid Baecker Avila ${ }^{3}$ \\ https://orcid.org/0000-0003-4868-3026
}

\begin{abstract}
${ }^{1}$ Universidade Federal de Santa Catarina, Centro de Ciências da Educação, Departamento de Estudos Especializados em Educação, Programa de Pós-Graduação em Educação, Florianópolis, SC, Brasil

${ }^{2}$ Universidade do Extremo Sul Catarinense, Programa de Pós-Graduação em Educação, Criciúma, SC, Brasil

${ }^{3}$ Universidade Federal de Santa Catarina, Centro de Ciências da Educação, Departamento de Estudos Especializados em Educação, Florianópolis, SC, Brasil
\end{abstract}

\section{Em tempos de desumanização: a emergência da crítica ontológica no complexo educacional}

Resumo: Na atualidade a adaptação ao existente é uma realidade que se impõe, implicando, também, numa necessária compreensão do tempo presente e de uma crítica ontológica que nos permita não só compreender o papel da educação e do conhecimento, senão também costurar estratégias de formação e articulação em que a teoria recupere seu papel fundamental de orientação da prática. Contrariando o espírito do tempo, entendemos que as implicações entre ontologia e conhecimento para o debate da educação apresentam, explícita ou implicitamente, a questão de por que ontologia e por que uma crítica ontológica. Apresentamos neste texto o movimento dialético da dimensão ontológica e gnosiológica a partir de uma concepção de ser humano que possa gerar as possibilidades de interditar a ideia de que o sistema capitalista totalizante não pode ser superado. Ao contrário, é necessário um tipo de conhecimento que considere a totalidade, como nos oferece a ontologia crítica.

Palavras-chave: Crítica ontológica. Complexo educacional. Conhecimento.

In times of dehumanization: the emergence of ontological criticism in the educational complex Abstract: Adapting to the existent context in current days is a mandatory measure that implies understanding present times. It also implies comprehending an ontological critique that explains the role of education and knowledge, at the same time as supporting educational and connection strategies that restore to theory its fundamental role of guiding the practice. Contrary to zeitgeist, ontology and knowledge implications on the debate about education, explicitly or implicitly pose the question why ontology and why an ontological critique? In this article, we present the dialectical movement of the ontological and gnosiological dimension based on a conception of human beings that can generate the possibilities of banning the idea that the totalizing capitalist system cannot be surpassed. On the contrary, we need a form of knowledge that considers totality, as offered by critical ontology.

Keywords: Ontological critique. Educational complex. Knowledge.

Recebido em 05.02.2019. Aprovado em 17.09.2019. Revisado em 31.10.2019.

(C) O(s) Autor(es). 2020 Acesso Aberto Esta obra está licenciada sob os termos da Licença Creative Commons Atribuição-Não Comercial 4.0 Internacional (https://creativecommons.org/licenses/by-nc/4.0/deed.pt_BR), que permite copiar, distribuir e reproduzir em qualquer meio, bem como adaptar, transformar e criar a partir deste material, desde que para fins não comerciais e que você forneça o devido crédito aos autores e a fonte, insira um link para a Licença Creative Commons e indique se mudanças foram feitas. 


\title{
Introdução
}

\begin{abstract}
Como definir padrões epistemológicos, educacionais, éticos ou políticos se não se dispõe mais da chancela da concepção moderna e iluminista de racionalidade? Como pensar a ética ou o conhecimento sem o suporte de uma subjetividade livre, racional, consciente e dotada de vontade e responsabilidade? Ou de uma intersubjetividade também racional, consciente e responsável, capaz de justificar seus atos e responder por eles? Como e o que ensinar se todas as interpretações e perspectivas são igualmente válidas e sem referente? Como e o que ensinar se a mudança conceitual repousa na persuasão e não na razão? Se conceitos científicos são apenas mais um entre os múltiplos jogos de linguagem? (MORAES, 2001, p. 12).
\end{abstract}

No campo educacional toda prática é precedida por uma compreensão de como o mundo é, portanto dependendo da ontologia com que se figura esse mundo pode-se referendar práticas reprodutivas que se limitam à repetição do existente ou configurar o mundo de maneira radicalmente distinta, é o modo como o mundo é significado que faculta e referenda determinada prática (DUAYER, 2010). As repercussões desse debate, no campo educacional, são inúmeras, afetando profundamente a prática educativa e nossa consciência sobre ela.

Nosso horizonte de possibilidades é condicionado pelo padrão vigente de reprodução social, mas justamente pelo fato do ser humano ser capaz de representar o mundo mediante sua capacidade de ideação nos permite pôr novas objetividades, para além da simples reprodução da sociabilidade. Nisso reside o momento de liberdade em que a transformação social se torna possível. Lukács (2012, p. 27) afirma que o passo "[...] dado por Marx, para avizinhar-se da questão decisiva, consistiu em conferir uma posição central ao espelhamento dialético da realidade objetiva", pois se realidade e pensamento fossem uma mesma coisa os seres humanos estariam impedidos de pôr novos fatos ontológicos.

A prática educativa é uma prática social e tem múltiplas dimensões que faz com que seu objeto seja complexo, pois ele abrange no interior de seu movimento a produção de conhecimentos, as escolhas dos saberes que serão considerados como válidos para a transmissão, os processos de formação dos diferentes sujeitos e os diversos níveis, as relações ensino e aprendizagem, entre outras, como também a relação com diferentes esferas da totalidade social, política, econômica e jurídica que impactam as especificidades próprias desta prática. Um projeto educacional é um projeto político, cultural e ético que se orienta por uma compressão de sujeito, de realidade, que em certa forma define o sentido e o entendimento de formação humana.

Nesse contexto, a educação, como complexo parcial, é uma prática social privilegiada e desempenha um duplo papel, pode servir como instrumento de adaptação às relações existentes, contribuindo assim para a manutenção do status quo, ou, ao contrário, pode servir, tendo como base a ontologia crítica, como instrumento de resistência e luta, contribuindo para a superação do atual quadro social (MORAES, 2007). Lamentavelmente, a adaptação ao existente se configura uma realidade cada vez mais presente, implicando, também, uma contundente busca analítica das gêneses des-

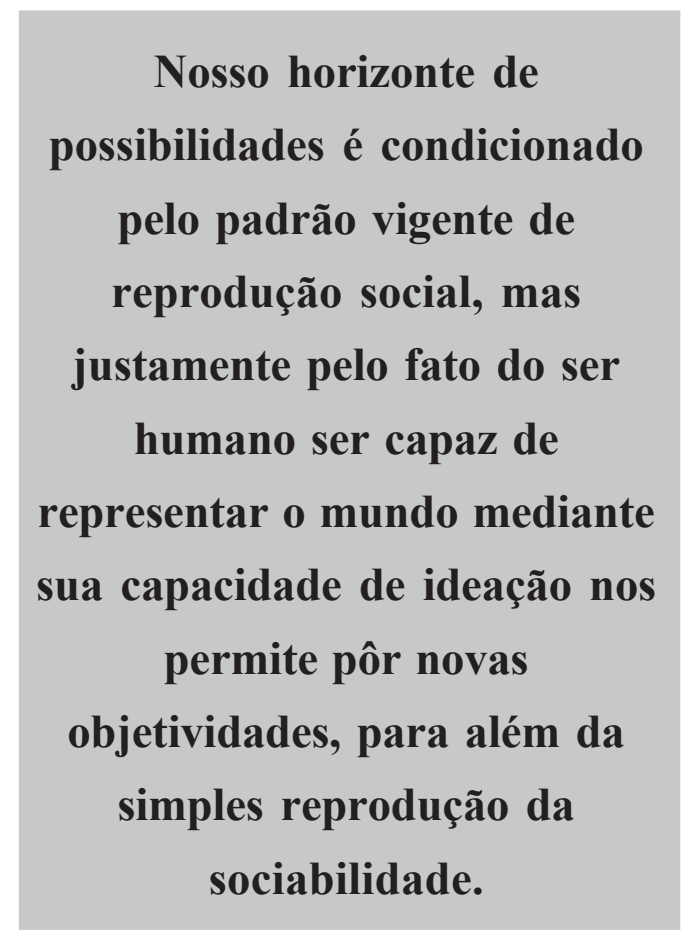
te problema, colocando a necessidade de uma crítica ontológica que nos permita não só compreender o papel da educação e do conhecimento, senão também costurar estratégias de formação e articulação em que a teoria recupere seu papel fundamental de orientação da prática.

Contrariando o espírito do tempo, entendemos que as implicações entre ontologia e conhecimento para o debate da educação apresentam, explícita ou implicitamente, a questão de porquê ontologia e porque uma crítica ontológica. Em tempos pragmáticos, quando homens e mulheres e suas relações definem-se e encontram inteligibilidade em sua utilidade e adaptabilidade, qual o sentido de se indagar pelo ser social e sua especificidade? Primeiramente podemos dizer que uma abordagem ontológica implica expressar a materialidade do ser humano histórico-social e essa premissa indica, desde já, uma árdua e complexa tarefa de desentranhar os tortuosos caminhos da relação com a realidade. Lessa (1996) responde a questão indicando que as sucessivas derrotas em superar o capital geraram uma ilusão de que os seres humanos não são capazes de construírem conscientemente sua história. Esse processo conduziu à revitalização da concepção 
liberal e com ela a ideia de que a ordem capitalista corresponde a uma pretensa essência humana. Essência essa que nos define como proprietários privados que têm suas relações com os outros mediadas pelos interesses egoístas. Assim, conforme já nos apontou Marx, a essência do homem capitalista foi elevada à essência capitalista do homem.

Procurando avançar nessa discussão, apresentamos neste texto o movimento dialético da dimensão ontológica e gnosiológica, a partir de uma concepção de ser humano que possa gerar as possibilidades de interditar a ideia de que o sistema capitalista totalizante não pode ser superado. Ao contrário, é necessário um tipo de conhecimento que considere a totalidade, que o materialismo histórico e a ontologia crítica nos oferecem.

\section{A dimensão ontológica e a crítica ao complexo educacional}

A compreensão do complexo educacional, a partir de uma crítica ontológica à concepção de educação nessa sociabilidade, torna-se um desafio e também uma necessidade que urge em contínua desumanização. Em outros contextos explicitamos o grave problema de limitar, nessa sociabilidade, aos sujeitos cognoscentes a capacidade de expandir e ampliar as possibilidades do conhecer as múltiplas dimensões que a realidade, em movimentos contraditórios, nos apresenta. Isso se verificou nas propostas de formação que vêm desde a década de 1990 - com as renovadas reformas de educação em toda América Latina - e as leis de educação e seus desdobramentos, e não separado destas, as diretrizes de formação com propostas de ensino e de aprendizagem no contexto de uma formação humana nos liames da reprodução capitalista. Esse impacto na educação de maneira geral e de forma estrita na formação e na produção de conhecimento se acentua na atualidade, evidenciado por um discurso moralista e religioso, travestido sob um véu de progresso. A emergência dessas duas dimensões retira, do campo social, processos de objetividade na compreensão dos fenômenos, graus de racionalidade necessária para poder realizar análises complexas. Nessa direção, fecha saídas que permitam entender a própria atividade historicamente datada dos sujeitos, mantendo-os nos limites asfixiantes de uma vida cotidiana que, em vez de se expandir, se adapta às propostas salvacionistas de um mundo melhor.

Preocupamo-nos com a noção de conhecimento predominante na sociedade contemporânea e em que ontologias elas se sustentam, assim como Lukács já indicou. Qualquer enunciado ou ação humana está pautado em uma noção de como o mundo é. Embora a atualidade seja marcada por uma supressão nominal da ontologia, pretendemos reafirmar que: 1) todo conhecimento pressupõe uma ontologia, mesmo que realize uma negação nominal; 2) questionar quais os motivos da necessidade contemporânea de supressão da ontologia na ciência indicando algumas consequências para o campo educacional. Nesse sentido, procuramos caracterizar o conhecimento como atividade do ser humano, ação realizada no âmbito do ser social, o qual encontra seu fundamento na efetividade em si do objeto cognoscível - a ontologia.

Para melhor compreender este processo vamos explicitar de forma sucinta o movimento de secundarização da dimensão ontológica, sob predomínio da gnosiologia ocorrido na modernidade, a partir do filtro da crítica lukacsiana. $\mathrm{O}$ autor magiar situa essa problemática a partir do enfraquecimento da metafísica grega e do domínio da concepção teológica da ontologia sobre as visões de mundo. A ontologia religiosa, dominada pelo cristianismo, refuta toda visão de mundo baseada sobre o plano científico e afirma como única realidade a objetivação da aliança religiosa, negando o sentido terreno da vida. Porém, a estrutura bimundana presente na perspectiva grega é mantida. Nas palavras de Lukács (2012, p. 36-37):

[...] uma concepção teleologicamente fundada do mundo dos seres humanos, no qual se realiza o seu destino, no qual seu comportamento define sua salvação ou danação, e do mundo compreensivo, teleologicamente ainda superior, cósmico-transcendente, de Deus, cujo ser constitui a garantia ontológica última da indubitabilidade do poder de Deus na realidade terrena; o cosmo é, portanto, fundamento ontológico e o objeto visível do poder de Deus.

A Igreja e a religião mantêm essa base ontológica por muitos séculos, mesmo com teorias divergentes e a necessidade de adaptação da moral cristã aos dados sociais e políticos cada vez existentes.

Porém, [observa Lukács,] apesar de todas essas transformações, permaneceram inabalados os princípios mais importantes da ontologia religiosa: o caráter teleológico do cosmo e do desenvolvimento histórico, a construção antropocêntrica (e, por essa razão, necessariamente geocêntrica) do cosmo que, governado pela onipotência de Deus - exercida teleologicamente -, faz da vida humana terrena o centro do universo, um centro próprio do ser humano e protegido pela transcendência. (LUKÁCS, 2012, p. 37). 
Enquanto a igreja conseguiu realizar as adaptações entre ontologia e moral pôde garantir seu predomínio, refutando a imagem de mundo "normal-cotidiana" e aquela científica, considerando-a como heresia, adaptandoa para ser expressa em termos religiosos ou, quando isso não era possível, "nos casos extremos se oferecia à ciência um tipo de asilo intelectual com a teoria da dupla verdade" (LUKÁCS, 1976, p. 16, tradução nossa).

O cardeal Bellarmino é figura central no contexto da ontologia religiosa que estamos apresentando. Teve forte presença nos processos da inquisição de Giordano Bruno, Tommaso Campanella e Galileu Galilei. Neste último, alerta Galileu de que a teoria copernicana deveria ser discutida somente como uma hipótese matemática (RUI; MORATÓ, 1996). O que Bellarmino faz neste ponto é distinguir a verdade revelada da verdade especulativa ou filosófica. Sem desfazer o primado da primeira, vai ao encontro do que Abbagnano (1998) chama de fideísmo, ou seja, admite-se a verdade filosófica, racional, porém inferior à verdade revelada pelas escrituras.

Posteriormente às pesquisas de Copérnico, Kleper e Galileu torna-se socialmente impossível reprimir as consequências de suas descobertas, que fogem ao controle da ontologia religiosa. "A derrubada científica do sistema geocêntrico do mundo até pôde ser provisoriamente condenada como heresia, com todas as consequências daí decorrentes, mas sua vigência social, seus efeitos sobre a práxis social não podiam mais ser detidos com tais expedientes." (LUKÁCS, 2012, p. 38). Reforçada pela explosão do conflito com Galileu, verifica-se, então, uma mudança na ontologia religiosa: se até então a teoria da dupla verdade mantinha a ciência à sua sombra, com a formulação bellarminiana, "[...] a Igreja, a ideologia religiosa oficial, recorria à teoria da dupla verdade para salvar ao menos temporariamente aquilo de sua ontologia de que não gostaria de renunciar". (LUKÁCS, 2012, p. 38).

Essa posição, assinala Lukács (2012), possui sempre uma atitude cínica que, ao mesmo tempo em que demonstra a percepção instintivamente justa do novo estado das coisas por parte da Igreja, expressa sua orientação diante da nova classe dominante em ascensão, a burguesia. Para ele esse caráter cínico é reforçado, não só "[...] quando [...] se trata de obter um pouco de espaço para um conhecimento antes reprimido ou condenado à extinção, mas de, com sua ajuda, manter intacta no plano organizativo a validade oficial de uma ontologia" (LUKÁCS, 2012, p. 38).

O desenvolvimento do processo produtivo burguês baseado na utilização dos novos conhecimentos que lhe permitia dominar melhor as forças naturais entrava em conflito com as normativas teológicas, pois para a burguesia, "[...] o desenvolvimento irrestrito das ciências, sobretudo das ciências naturais, era uma questão vital". (LUKÁCS, 2012, p. 39). Foi isso que fez com que o novo posicionamento frente à objetividade real - a questão se a verdade das ciências naturais reflete efetivamente a realidade objetiva ou torna possível a manipulação - dominasse a filosofia burguesa e determinasse os problemas ontológicos até hoje, assim estava aberto o caminho ao predomínio da gnosiologia.

Esta nova possibilidade do avanço do conhecimento, para Moraes (1995) marca, de certa forma, a época moderna, em que pensadores como Descartes, Locke e Kant elevam a temas centrais a serem inquiridos pela filosofia os problemas do conhecimento e da dúvida epistemológica. Libertos dos grilhões que os prendiam até então, homens e mulheres postulam sua liberdade e emancipação dos laços da fé que tolhiam seus antepassados medievais, cujas certezas neles originavam-se e eram plenamente conhecidas, uma vez que "o cristão sabe o que sabe e tem certeza de seu próprio saber pela fé" (MORAES, 1995, p. 123).

Porém, descreve Lukács (1976), como a Igreja não foi capaz de controlar os efeitos práticos das descobertas científicas, perdeu, também, o controle sobre a primazia da ontologia teológica das visões de mundo. Com o desmoronamento do aparato econômico e político da sociabilidade feudal, desaparece este sólido ponto de apoio e os seres humanos da modernidade, livres das amarras da religião, encontram em si mesmos o fundamento da verdade e da liberdade, decidem o que pode ser conhecido, o que é o conhecimento e o que é a certeza.

Nessas circunstâncias, explicita Moraes (1995), altera-se fundamentalmente a base de relacionamento do ser humano com o mundo que se torna o subjectum, o fundamento de tudo que existe quanto a seu aparecer e a sua verdade, ou seja, a sociedade e a cultura passam a ser compreendidas como obra humana. Descartes é quem elabora o fundamento metafísico deste modo de conhecer. "O cogito [pensamento] é o subjectum [fundamento] de toda certeza, uma vez que em si mesmo e por si mesmo fundamenta todas as possibilidades de qualquer fenômeno." (MORAES, 1995, p. 123). O existente não é mais o que está presente - como para o hypokeimenon grego - ou o que pertence à ordem da criação divina - como para a ontologia religiosa -, mas o que se coloca em oposição ao sujeito, o que se coloca como objeto. Sujeito e objeto são, a partir daí, tomados como duas entidades diferentes por natureza e intrinsecamente separadas. Oposto ao ser humano como sujeito, representado por ele, o que existe no mundo passa a ter sentido somente nesta relação (MORAES, 1995). $\mathrm{O}$ único conhecimento concebido como verdadeiro é o que alcança representações mentais acuradas de um mundo objetivo, real, oposto e independente da mente do sujeito cognoscente.

Dito de outro modo, o cogito pode ser concebido como fundamento não por ser apenas o modelo, mas porque é a condição de qualquer certeza; para poder representar - colocar o mundo diante de si como objeto 
- é preciso que se conheça a si mesmo como quem representa o que é representado, como quem propõe o que é proposto (MORAES, 1995).

Em seus múltiplos feitios, as questões versando sobre as possibilidades do conhecimento e sobre o fundamento da verdade irão nortear as teorias do conhecimento a partir de Descartes. Ademais, contemporâneas de uma ciência da natureza caracterizada pelo experimento e por uma linguagem formalizada, tais teorias buscam, também, estabelecer e delimitar suas condições de possibilidade e suas justificativas lógico-psicológicas.

Com o positivismo do século XIX, porém, algo de novo se introduz na tradicional indagação sobre a gnosiologia: a teoria do conhecimento é substituída por uma teoria da ciência e a filosofia, de análise das possibilidades do conhecimento humano, é reduzida a uma metodologia da ciência. De acordo com Lukács (1976, p. 47), "as grandes revoluções que se iniciavam nas ciências da natureza pareciam oferecer um fundamento para excluir completamente da gnosiologia as categorias ontológicas decisivas da natureza, como, sobretudo, a categoria da matéria". Tal movimento, segundo o autor magiar, passa de um ceticismo, ou mesmo pessimismo, especialmente no liberalismo, para uma confiança no poder ilimitado da manipulação das massas. De fato:

[...] se a ciência não se orienta para o conhecimento mais adequado possível da realidade existente em si, se ela não se esforça para descobrir com seus métodos cada vez mais aperfeiçoados essas novas verdades, que necessariamente são fundadas também em termos ontológicos e que aprofundam e multiplicam os conhecimentos ontológicos, então sua atividade se reduz, em última análise, a sustentar a práxis no sentido imediato. (LUKÁCS, 2012, p. 47).

Quando a ciência permanece no nível do imediato sua atividade transforma-se numa manipulação dos fatos que interessam à prática imediata, como requerido pelo cardeal Bellarmino, na tentativa de salvar a ontologia teológica. Lukács (2012) faz referências ao combate de Lenin a essa tendência. Para o autor húngaro, Lenin atenta para a diversidade filosófica existente entre o conceito ontológico de matéria e o tratamento científico concreto de seus modos de manifestação apreensíveis e, também, à inadmissibilidade deste procedimento extrair conclusões diretas sobre a própria matéria.

Com a exclusão da efetividade existente em si, ou mesmo considerada irrelevante para a metodologia da ciência, deriva uma homogeneização da realidade existente em si e da forma de espelhamento (o conhecimento) em uma única objetividade.

Para que nossa questão possa ser melhor explicitada, talvez seja interessante situar a retomada da questão ontológica no século XX, mesmo que em linhas bastante gerais.

A hegemonia da gnosiologia, observa Tertulian (1996, no prelo), encontrou forte questionamento no século XX, quando da retomada da ontologia como questão central na filosofia nas obras de Heidegger, Hartmann e Lukács. A partir da metade do século XX, principalmente com as correntes pós-modernas e pós-estruturalistas, essa discussão se articula a uma outra, que é a da negação da existência do real independente das ações humanas ou das formas de sua apreensão.

Segundo Tertulian (1996, no prelo), a retomada da ontologia situa-se no âmbito de uma crítica precisa: ao predomínio gnosiológico no percurso do pensamento ocidental, sobretudo na época moderna, e às consequentes concepções de conhecimento e de verdade nele implícitos. Em seu lugar, Heidegger, Hartmann e Lukács irão sustentar, de modo bastante distinto, o primado do ser efetivamente existente como centro de suas reflexões.

Dos três pensadores, é Lukács $(2012,2013)$ quem desenvolve a reflexão sobre a determinação ontológica do ser social seguindo a orientação marxiana, com base nas categorias gerais do ser. No ser humano surgem novas categorias que operam sobre as categorias gerais em uma relação de superação-continuidade, isto é, ao mesmo tempo em que o ser social supera os limites postos pelos seres inferiores, superando-os, não elimina as suas determinações, processo a que Marx refere-se como recuo das barreiras naturais.

Lukács (1990, p. 3, tradução nossa) observa que o domínio da gnosiologia, que culmina em Kant, foi tão expressivo nos últimos séculos que levou "a opinião pública competente" a esquecer que o seu objetivo principal estava em "fundamentar e garantir o direito à hegemonia científica da ciência natural desenvolvida a partir do Renascimento, mas de fazê-lo em termos que ficasse salvo - cada vez na medida socialmente requerida - o espaço ideológico que a ontologia religiosa tinha conquistado historicamente". Assinala que o compromisso bellarminiano nunca conseguiu bloquear totalmente as repercussões que a ruptura com a posição cósmica e ontologicamente espacial da terra pode ter sobre o plano da concepção de mundo. Isso faz surgir uma polarização na filosofia burguesa: por um lado estão os que buscam completar coerentemente a nova ontologia, acolhendo e desenvolvendo a herança do Renascimento; por outro, estão pensadores importantes e influentes que buscam dar uma fundação gnosiológica ao cinismo político-eclesiástico de Bellarmino. Lukács sublinha a esse respeito: 
Basta mencionar, [...] Berkeley e Kant, - a despeito de todas as diferenças entre ambos até em questões de princípio. No essencial, o elemento comum das aspirações de ambos consiste em demonstrar gnosiologicamente que não é possível atribuir significado ontológico aos nossos conhecimentos do mundo material [...] Em ambos os casos o funcionamento do conhecimento da natureza - em cada ciência singular -, em sua objetividade prático-imanente, é deixado gnosiologicamente intacto, ao lado de uma rejeição - igualmente gnosiológica - de toda "ontologização" de seus resultados, de todo reconhecimento da existência de objetos em si, independentes da consciência cognoscente [...]. (LUKÁCS, 2012, p. 39-40).

Na ontologia geral apresenta-se o movimento idealista subjetivo, que "[...] com base numa orientação gnosiológica, havia combatido o materialismo filosófico por causa do empenho deste em derivar da materialidade todo e qualquer ser" (LUKÁCS, 2012, p. 54), erguendo um singular mundo pensado, embora o ser em-si ontológico - permaneça incognoscível por princípio $^{1}$, pois:

[...] [o ser] em si deve permanecer para todo conhecimento um fantasma inalcançável ou um além sempre abstrato [...]. Sempre subsiste, portanto, nos idealistas subjetivos, uma visão de mundo - muito variada, ou mesmo contraposta - que refuta apenas a "presunção materialista" de explicar o mundo por si mesmo. (LUKÁCS, 2012, p. 54).

Com a debilidade do predomínio do pensamento kantiano no curso do século XIX, Lukács observa o surgimento de uma corrente idealista no pensamento positivista - com suas origens em Mach, Avenarius, Poincaré $^{2}$-, a qual cria um terreno que se pretende nem idealista-subjetivo nem materialista-objetivo, mas um meio filosófico que exclui do campo do conhecimento toda ontologia, garantindo, sob essa suposta neutralidade, um conhecimento científico puro.

Os assim chamados elementos do mundo (por exemplo, a unidade de sensação e coisa) são declarados um terreno, nem objetivo nem subjetivo, a partir do qual essa corrente quis construir uma nova filosofia científica que excluísse toda ontologia. Com isso, nada mais natural que o distanciamento em relação a Kant, apesar da múltipla afinidade gnosiológica com o neokantismo, tenha sido energicamente acentuado, de modo a evidenciar que a nova filosofia era adversária de toda visão de mundo, inclusive das idealistas. (LUKÁCS, 2012, p. 44-55).

Uma vez que a separação do mundo sob o modelo da "crítica da razão pura" e da "crítica da razão prática" se revelava impraticável, pois em última análise podia somente separar um conhecimento puro da natureza de uma moral pura, surgem:

[...] contínuos compromissos metodológicos que põem de lado o problema ontológico fundamental da especificidade ontológica do ser social e enfrentam as dificuldades cognitivas dos setores singulares de modo puramente gnosiológico ou puramente metódico, epistemológico. (LUKÁCS, 2012, p. 26).

Para os neokantianos isso se dá por simples coerência, uma vez que o ser da coisa em si não pode ser conhecido. "Aqui o neokantismo do final do século aproxima-se bastante do positivismo da época de Mach, Avenarius etc." (LUKÁCS, 2012, p. 26).

Somente em Marx a ontologia recebe a descrição correta que supera a analogia da relação entre gnosiologia e métodos específicos das ciências singulares, pois o que passa a ser conhecido são os fundamentos gerais de qualquer ser. "Antes de tudo, ele vê com clareza que há toda uma série de determinações categoriais, sem as quais nenhum ser pode ter seu caráter ontológico concretamente apreendido. Por essa razão, a ontologia do ser social pressupõe uma ontologia geral.” (LUKÁCS, 2012, p. 27). Evidencia-se a relação existente entre os níveis de ser, em que, nas formas mais compostas e complexas as categorias da ontologia geral permanecem presentes como momentos superados. Superar em sentido hegeliano que inclui também o conservar.

Lukács desenvolve sua ontologia com uma visão histórica do real. Sobre esse aspecto Duayer (1995, p. 107), ao discutir a historicidade na ontologia do ser social marxiana, observa: "Tal concepção não nega, desse modo, a historicidade das categorias contidas em outros sistemas categoriais. Para colocá-lo na conhecida formulação de Marx, isto equivale a dizer que as categorias são formas de ser, determinações do existente".

Embora tratando de uma questão central da filosofia, Lukács tem sua preocupação voltada às questões práticas emergentes do período em que vive e, por isso mesmo, vê a necessidade de recolocar a questão da 
ontologia no centro da reflexão, sem que isso signifique o abandono da gnosiologia, pois o conhecimento, mesmo que aproximativo, da realidade constitui o locus de ação do ser social.

Segundo Scarponi (1976, p. 9, tradução nossa), Lukács entendia que a nova realidade capitalista objetivava controlar as ciências para melhor manipulá-las, o que torna o método neopositivista, "que é ao mesmo tempo representante teórico e instrumento da manipulação", o adversário direto do marxismo.

Trata-se de um verdadeiro e próprio movimento internacional que encontra origem na necessidade do capitalismo de manipular o mercado, [assinala Scarponi], mas que depois se autonomiza e se desenvolve em uma forma geral de consciência em que impera exclusiva uma gnosiologia que quer substituir o conhecimento da realidade pela manipulação dos objetos indispensáveis na práxis imediata. A verdade é suplantada pelo alcance dos fins prático-imediatos, neste movimento ideológico geral não estão somente as correntes filosóficas de maior prestígio intelectual neste período (neokantismo, positivismo, empirocriticismo, pragmatismo, behaviorismo e enfim o neopositivismo, com o seu pendant, o existencialismo), mas também a religião codificada, que busca com a ciência moderna o 'compromisso bellarminiano' da dupla verdade. (SCARPONI, 1976, p. 9, tradução nossa).

Se durante quase todo o século XX a discussão situava-se claramente entre a ontologia e a gnosiologia ou a epistemologia, a partir das últimas décadas o debate ganha novas características. Com a suposta derrocada da epistemologia, com a chamada crise da modernidade e seus sub-produtos de agenda pós-moderna (WOOD, 1999), os pós-ismos (MORAES, 1996) determinam a suposta morte do sujeito, passam a defender que a verdade legitima-se na cultura ou na política, ou então é uma construção criada pelos homens, uma crença socialmente justificada.

$\mathrm{O}$ debate instaurado nestes termos passou a polarizar em torno dos que consideram que o real existe independentemente de o conhecermos ou não, e justamente por isso, é cognoscível, e os que consideram o real incognoscível e até mesmo inexistente, ou que só ganha existência como produto do conhecimento ou da cultura - inclusa a religiosa.

Consideramos a atualidade do debate referido acima como um dos pontos a serem enfrentados no contexto da produção do conhecimento em educação. Nesse sentido, só é possível pactuarmos com a idéia que o real existe independente de nosso conhecimento sobre ele, se possuímos uma noção do que é o ser social. Pois se realidade e pensamento fossem uma mesma coisa os seres humanos estariam impedidos de pôr novos fatos ontológicos, ou seja, estabelecerem novas efetividades sociais, e o presente seria apenas uma repetição do passado, com ausência de qualquer futuro possível.

\section{Considerações finais}

Acreditamos em processos de conhecimentos e a possibilidade de emancipação social, já que a prática humano-social é uma "prática teleológica, intencional, finalística" e, por isso mesmo, "dependente crucialmente de uma significação ou figuração de mundo mais ou menos unitária e coerente" (DUAYER, 2010, p. 3). Nessa direção, a significação teórica e prática da realidade não pode permanecer nos marcos empíricos que a delimitam já que isto é um obstáculo para apreensão da realidade objetiva. Diferentes correntes pós-modernas, e em especial o neopragmatismo não negam a existência da realidade, mas seus axiomas e princípios refutam, porém, a possibilidade de a ela ter acesso fora do âmbito da cultura, da linguagem, dos interesses humanos. Isto consiste em que o sistema de significações que apregoam torna o acesso a ela impossível ou, ao menos, como indicamos, limitado a espaços de conhecimento que não indagam nem aprofundam os nexos e as relações que configuram o movimento real dos fenômenos.

O conhecimento é uma forte ferramenta teórica que possibilita analisar e desnudar os processos de desvalorização da formação humana e da pesquisa em um contexto de desumanização. Mas também pode obstaculizar ou consolidar o status quo. Consideramos esse debate imprescindível para que a educação efetive sua finalidade precípua, o que exige a apreensão da especificidade da formação do ser social, como explicita Lukács (2013, p. 130-131):

É possível que a peculiaridade específica do ser social fique ainda mais evidente no complexo de atividades que costumamos chamar de educação. Naturalmente, também para isso há certas analogias nas espécies animais superiores. Estas, contudo, empalidecem quando ponderamos que o auxílio que os animais adultos dão aos seus filhotes se reduz à apropriação de uma vez por todas, com a destreza correspondente à espécie, de certos comportamentos que permanecem indispensáveis por toda a sua vida. Porém, o essencial da 
educação dos homens, pelo contrário, consiste em capacitá-los a reagir adequadamente aos acontecimentos e às situações novas e imprevisíveis que vierem a ocorrer depois em sua vida. [...] Assim sendo, a problemática da educação remete ao problema sobre o qual está fundada: sua essência consiste em influenciar os homens no sentido de reagirem a novas alternativas de vida de modo socialmente intencionado.

Isso reforça a tese marxiana de que o ser social reproduz a si mesmo em determinadas condições sóciohistóricas. Se nos limitarmos ao imediatamente dado, condenamos as novas gerações ao limite de desenvolvimento dado pela vida cotidiana. Isso dificilmente apresentará novas situações e, pior ainda, as novas gerações terão dificuldades em escolher com ciência o modo socialmente intencionado, pois agirão pela intenção social do cotidiano que, no atual contexto, defende os interesses de um pequeno grupo que detém a hegemonia da direção social. Um conhecimento que se limita ao imediato da prática cotidiana não pode oferecer outra possibilidade de formação. Lukács é imprescindível para refletirmos sobre que conhecimento queremos oferecer para apreensão pelas novas gerações que, em última análise refere-se à questão de que ser humano queremos ajudar a formar.

No campo educacional isso vem se refletindo da seguinte forma: o modo de operar do ato educativo no cotidiano escolar transforma essa experiência em limite da inteligibilidade (MORAES, 2007, p. 2). A atividade docente acaba por se limitar estritamente ao cotidiano e ao pragmático, e como indicamos, se o que configura o mundo social é a experiência cultural individual imediata que, entre outras coisas, interdita qualquer possibilidade de que existam conhecimentos universais a serem transmitidos pela escola, esta, por sua vez, torna-se apenas um espaço entre muitos outros de trocas e de compartilhamentos de crenças culturalmente estabelecidas. Por outro lado, como assevera Moraes (2007, p. 6):

[...] as teorias que são construídas sobre esta base justificam-se por sua adequação empírica e por sua utilidade instrumental. Concepções equivocadas podem perfeitamente se amoldar à manipulação instrumental de objetos e estruturas da realidade, permitindo que seres humanos respondam às demandas da vida cotidiana, ou se quisermos do chão da escola.

Um dos resultados visíveis dessas concepções é o comprometimento da atividade educacional, já que se desvaloriza todas as dimensões do conhecimento - conhecimento cotidiano e as complexificações necessárias - que são fundamentais para o papel central da educação, como assinala Lukács: sua essência consiste em influenciar os homens no sentido de reagirem a novas alternativas de vida de modo socialmente intencionado, mas como alcançar a liberdade, a emancipação, a verdade se as alternativas se diluem em meras adaptações instrumentais?

Diante da contradição posta pelo capitalismo - entre, por um lado, a necessidade de se educar o trabalhador para apropriar-se das qualificações necessárias exigidas pelo processo produtivo e, por outro, a constante tentativa de impedir que o trabalhador domine o conhecimento em níveis que possa enfrentar sua exploração - o ideário contido em propostas de educação e de formação centradas na perpetuação do senso comum e da distração proposital da não existência de uma vida mais ampla, mais justa, mais livre, ajusta-se com perfeição à idéia de que o mais importante a ser adquirido não é o conhecimento, mas sim a capacidade de constante adaptação às mudanças no sistema produtivo. Desse modo, os destinos da educação:

[...] parecem estar diretamente articulados às demandas de um mercado insaciável e da sociedade dita do "conhecimento". Como decorrência, os sistemas educacionais dos vários países sofrem pressões para construir ou consolidar escolas mais eficientes e aptas a preparar as novas gerações e, além da atualização do sistema escolar, a criarem mecanismos para uma educação continuada, uma educação para toda a vida. A educação, enfim, adequada à sociedade na qual todos os lugares são lugares de aprendizagem - all places are learning places (MORAES, 2001, p. 2, grifo do autor).

A oposição ao sistema capitalista exige-nos também convocar interesses e recursos que unifiquem ao invés de fragmentar a luta anticapitalista. Se numa primeira instância são os interesses e recursos da classe, a mais universal força isolada capaz de unificar lutas libertadoras diferentes, ao final falamos sobre os interesses e recursos da nossa humanidade comum, na convicção de que, não obstante nossas muitas divergências, há certas condições fundamentais e irredutivelmente diferentes de bem-estar humano que o modo de vida regido sobre as orientações do capital não pode nem poderá satisfazer. Nesse sentido, esta compreensão do complexo educacional, a partir da ontologia crítica que procura realizar uma crítica à concepção de educação nesta sociabilidade, torna-se um desafio e ao mesmo tempo, uma necessidade que urge em tempos de contínua desumanização. 


\section{Referências}

ABBAgnanO, N. Dicionário de Filosofia. 3. ed. São Paulo: Martins. Fontes, 1998.

DUAYER, M. Manipulação ou Emancipação? pragmatismo e ciência econômica. 1995. Tese (Professor Titular) - Universidade Federal Fluminense, Niterói,1995.

DUAYER, M. Relativismo, certeza e conformismo: para uma crítica das filosofias da perenidade do capital. Revista da Sociedade Brasileira de economia Política, São Paulo, v. 27, p. 58-83, out. 2010.

LESSA, S. A ontologia de Lukács. Maceió: UFAL, 1996.

LUKÁCS, G. Para uma ontologia do ser social I. São Paulo: Boitempo, 2012.

LUKÁCS, G. Para a Ontologia do ser social II. São Paulo: Boitempo, 2013.

LUKÁCS, G. Per l'ontologia dell'essere sociale. Roma: Riuniti, 1976.

LUKÁCS, G. Prolegomeni All'Ontologia dell'Essere Sociale: questioni di principio di un'ontologia oggi divenuta possibilie. Milano: Guerini Associati, 1990.

MORAES, M. C. M. Comte e o Positivismo. In: HÜHNE, L. M. (org.). Profetas da Modernidade. Rio de Janeiro: UAPÊ/SEAF, 1995. p. 109-147.

MORAES, M. C. M. Os “pós-ismos” e outras querelas ideológicas. Perspectiva, Florianópolis, v. 14, n. 25, p. 45-59, jan. 1996. Disponível em: https://periodicos.ufsc.br/index.php/perspectiva/article/view/10856/10334. Acesso em: 06 ago. 2019.

MORAES, M. C. M. Recuo da teoria: dilemas na pesquisa em educação. Revista Portuguesa de Educação, Braga, v. 14, n. 1, p. 7-25, 2001. Disponível em: http://www.redalyc.org/pdf/374/37414102.pdf. Acesso em: 06 ago. 2019.

MORAES, M. C. M. Indagações sobre o conhecimento no campo da educação. In: REUNIÃO ANUAL DA ANPED, $30 ., 7-11$ out. 2007, Caxambu, MG. Anais [...]. Caxambu, MG: ANPED, 2007. p. 315-346. Disponível em: https://periodicos.ufsc.br/index.php/ perspectiva/article/download/2175-795X.2009v27n2p315

/15284. Acesso em: 10 ago. 2019.

RUI, A. M.; MORATÓ, J. C. Diccionario de filosofia. Barcelona: Herder, 1996. CD-Rom.

SCARPONI, A. Prefazione. In: Lukács, G. Per l'ntologia dell'essere sociale. Roma: Riuniti, 1976.

TERTULIAN, N. Georg Lukács e a reconstrução da ontologia na filosofia contemporânea. In: CONFERÊNCIA PROFERIDA NO PROGRAMA DE PÓS-GRADUAÇÃO EM EDUCAÇÃO DA UFCE, 1996, Recife. No prelo.

WOOD, E. M. O que é a agenda "pós-moderna"? In: WOOD, E. M.; FOSTER, J. B. Em Defesa da História: marxismo e pósmodernismo. Rio de Janeiro: Jorge Zahar, 1999. p. 7-22.

\section{Notas}

1 Lukács comenta a crítica de Kant que chama de "escândalo da filosofia“" o fato, sustentado por Berkeley, de que a existência das coisas fora de nós era admitida simplesmente por fé.

2 Mach(1838-1916), Avenárius (1843-1896) e Poincaré (1854-1912), são alguns dos filósofos que no final do século XIX começaram, cada qual a seu modo, a questionar o empirismo das ciências.

\section{Patricia Laura Torriglia}

patrilaura@gmail.com

Doutora pelo Programa de Pós-Graduação em Educação da Universidade Federal de Santa Catarina (UFSC) Professora do Departamento de Estudos Especializados em Educação, Centro de Ciências da Educação da Universidade Federal de Santa Catarina (UFSC)

\section{UFSC}

R. Eng. Agronômico Andrei Cristian Ferreira, 240-432 - Carvoeira

Florianópolis - Santa Catarina - Brasil

CEP: 88040-000

\section{Vidalcir Ortigara}

vdo@unesc.net

Doutor pelo Programa de Pós-Graduação em Educação da Universidade Federal de Santa Catarina (UFSC) Professor da Universidade do Extremo Sul Catarinense (UNESC) 


\section{UNESC}

Av. Universitária, 1105, Bloco Q - Bairro Universitário

Criciúma - Santa Catarina - Brasil

CEP: 88806-000

\section{Astrid Baecker Avila}

abaeckeravila@gmail.com

Doutora pelo Programa de Pós-Graduação em Educação da Universidade Federal de Santa Catarina Professora do Departamento de Estudos Especializados em Educação, Centro de Ciências da Educação da Universidade Federal de Santa Catarina (UFSC)

\section{UFSC}

R. Eng. Agronômico Andrei Cristian Ferreira, 240-432 - Carvoeira

Florianópolis - Santa Catarina - Brasil

CEP: 88040-000

Agência financiadora

Não se aplica.

\section{Contribuições dos autores}

O texto foi produzido com a participação dos três autores em todas as partes.

Aprovação por Comitê de Ética e consentimento para participação

Não se aplica.

\section{Consentimento para publicação}

Não se aplica.

\section{Conflito de interesses}

Não há conflito de interesses. 